\title{
New Version of Adaptive Speed Observer based on Neural Network for SPIM
}

\author{
Ngoc Thuy Pham ${ }^{1}$, Diep Phu Nguyen ${ }^{2}$, Khuong Huu Nguyen ${ }^{3}$, Nho Van Nguyen ${ }^{4}$ \\ ${ }^{1,2}$ Department of Electrical Engineering Technology, Industrial University of Ho Chi Minh City, Vietnam \\ ${ }^{3}$ Department of TE and Electrical Engineering, Ho Chi Minh City University of Transport, Vietnam \\ ${ }^{4}$ Department of Electrical and Electronics Engineering, University of Technology Ho Chi Minh City, Vietnam
}

\begin{tabular}{l} 
Article Info \\
\hline Article history: \\
Received May 21, 2018 \\
Revised Aug 30, 2018 \\
Accepted Sep 13, 2018 \\
\hline
\end{tabular}

\section{Keyword:}

Neural network

Sensorless vector control

Six phase induction motor drive

MRAS observer

Stator current based MRAS

\begin{abstract}
This paper presents a novel Stator Current based Model Reference Adaptive System (SC_MRAS) speed observer for high-performance Six Phases Induction Motor (SPIM) drives using linear neural network. The article aim is intended to improve performance of an SC_MRAS observer, which were presented in the literature. In this proposed scheme, the measured stator current components are used as the reference model of the MRAS observer to avoid the use of a pure integrator and reduce the influence of motor parameter variation. The adaptive model uses a two-layer Neural Network (NN) to estimate the stator current, which has been trained online by means of a Least Squares (LS) algorithm instead of uses a nonlinear Back Propagation Network (BPN) algorithm to reduce the complexity and computational burden, it also help to improve some disadvantages cause by the inherent nonlinearity of the BPN algorithm as local minima, two heuristically chosen parameters, initialization, and convergence problems, paralysis of the neural network. The adaptive model of the proposed scheme is employed in prediction mode, not in simulation mode as is usually the case in the literature, this made the proposed observer operate better accuracy and stability. In the proposed observer, stator and rotor resistance values are estimated online, these values thereafter were updated for the current observer and rotor flux identifier to enhance the accuracy, robustness and insensitivity to parameters variation for the proposed observer. The proposed LS SC_MRAS observer has been verified thought the simulation and compared with the BPN MRAS observer. The simulation results have proven that the speed is estimated a consequent quicker convergence, do not need the estimated speed filter, lower estimation errors both in transient and steady state operation, better behavior in low and zero speed operation.
\end{abstract}

Copyright (c) 2018 Institute of Advanced Engineering and Science. All rights reserved.

\section{Corresponding Author:}

Ngoc Thuy Pham,

Department of Electrical Engineering Technology,

Industrial University of Ho Chi Minh City,

12 Nguyen Van Bao street, ward 4, Ho Chi Minh City, Vietnam.

Email: Ngocpham1020@gmail.com

\section{INTRODUCTION}

In recent decades, the sensorless vector controlled SPIM drives are being vigorously developed for high performance industrial drive systems. The main advantages of the sensorless SPIM drives are higher torque density, greater efficiency, reduced torque pulsations, fault tolerance, and reduction in the required rating per inverter leg [1] and its reliable working characteristics and high failure tolerance. On the other hand, the sensorless drive have high reliability and mechanical robustness, save cost. The different techniques for the speed sensorless control of induction motors have been proposed. They usually are divided into two categories, the fundamental model based observers and anisotropies model based observers. Model- 
based estimation strategies include open-loop observers [2], sliding-mode observers [3], Extended Kalman Filter [4], Backstepping [5], model reference adaptive systems (MRAS) [6] and artificial intelligence (AI) [7]. Recent research also used predictive current control for sensorless IM drives [8]. Sensorless drives have been successfully applied in medium and high speed regions [9],[10], but low and zero speed operation is still a large challenge. In order to overcome these problems a high frequency voltage or current carrier were injected, needed to excite the saliency itself [11]. This method works well at low and near zero speed region. However, their major disadvantages are computational complexity, the need of external hardware for signal injection and the adverse effect of injecting signal on the machine performance. Due to its simplicity and ease of implementation the model based methods and especially MRAS based methods are, until now, the most widely used.The main problems associated with the low speed operation of model-based sensorless drives are related to machine parameter sensitivity, stator voltage and current acquisition, and flux pure integration problems [12]-[15]. Numerous MRAS have been proposed. Among them, the rotor flux MRAS first introduced by Schauder [16], Flux Backstepping Observer [17], both suffer from DC drift problems associated with pure integration and sensitivity to stator resistance variation, especially in the low speed region. In order to improve the performance of observer overcome the effect by sensitivity to stator resistance variation, online adaptation of the stator resistance [18], the pure integration problems, Extended Kalman Filter (EKF), a modified torque based on MRAS schemes have proposed in [19],[20], respectively. Although [19],[20] have shown that these approaches significantly improve the performance of the RFMRAS at low speed, these scheme remain the effected by the sensitivity to parameter variations. An improved rotor flux estimation to eliminate the pure integration problems and the effect of sensitivity to parameter variations for a Torque MRAS is proposed in [21]. Simulation and experimental results are shown the sensorless control drive operating at low and zero speeds, with both motoring and regenerative operations considered. The performance of the observer in low speed regenerating region and the performance of the transient and steady state were significantly improved at very low and zero rotor speeds. Analysis of the effect of parameter variation on the scheme performance has shown improved robustness against stator and rotor resistance variation over a wider range of load torques compared to results previously published for the conventional scheme. However, the estimated error increase at very low (3.14 rad/s) and zero speed range is recorded. The performance of the speed estimation in low speed regenerating region and the performance of the transient and steady state is not really satisfied.

Another approach, the stator current MRAS scheme has been introduced in [22]-[23]. [23] presents a stator current based MRAS speed observer using NN, which is an evolution of [22]. In this proposed scheme, to avoid the effect of a pure integrator and reduce influence of motor parameter variations, the measured stator current components are used as the reference model. The adaptive model of the proposed observer in [23] uses a two-layer NN with a BPN algorithm to estimate the rotor speed, an off-line trained multilayer feed-forward neural network is proposed as a rotor flux observer. The simulation and experimental results have proven that the significantly improvement operation performance in low and zero speed ranges, the lowest speed limit $25 \mathrm{rpm}$ (2.6 rad/s) was reported. The results in [23] also demonstrate that the proposed observer can handle the parameter variation problem with a good level of robustness, sensorless performance with a $50 \%$ variation in resistances at low speed, 25\% load. Although [23] can overcome the main problems associated with the low zero and speed operation, however, due to [23] the use of the nonlinear BPN algorithm to training a neural network causes some problem as local minima, paralysis of the neural network, need of two heuristically chosen parameters, initialization problems, and convergence problems. These make the performance of observer in [23] is not really as expected. The speed estimation error and oscillation phenomenon at low and zero increase. Other side, the adaptive model in [23] is used in simulation mode, which means that its outputs are fed back recursively, this also make reduce the accuracy and stability of the responses of observer. Finally, the use of two neural networks: the first is online trained for stator current estimation and the second is off-line trained for rotor flux estimation made increase the complexity and computational burden require high about hardware and time handle the data. This impose a large disadvantage of MRAS [23].

This paper proposes a novel SC_MRAS scheme. In the proposed LS_SC_MRAS observer, the reference model uses the stator current components to free of pure integration problems and insensitive to motor parameter variations. The new points in this SC_MRAS scheme are, first: Adaptive Model uses a two layer linear neural network, which is trained online by a linear LS algorithm, this algorithm requires the less computation effort and overcome some drawbacks, which cause by its inherent nonlinearity as in literature published before [23]. This significantly improves the performance of the proposed observer. Second: the adaptive model based on NN is implemented in the prediction mode. This improvement ensures the proposed observer operate better accuracy and stability. Third: the rotor flux, which is needed for the stator current estimation of the adaptive model, is identifier by the Voltage Model (VM) with the stator resistance value is estimated online to enhance the performance of the proposed LS_SC_MRAS observer, in 
addition, using VM will avoid the instability in the regenerating mode. In this proposed, rotor resistance value also has been estimated based on its variation proportional to that one of stator resistance, then the estimated resistance values were updated for the current observer to estimate the current exactly more. Finally, the modified Euler integration has been used in the adaptive model to solve the instability problems due to the discretization of the rotor equations of the machine enhance the performance of observer. The theoretical analysis is validated by simulation tests of the sensorless SPIM drive system under different operating conditions. Simulation results are given to compare the performance of the proposed observer with recent proposed observer [17],[20]-[23]. The comparison data have proven that the proposed LS_SC_MRAS observer are quicker convergence in speed estimation, better dynamic performances; lower estimation errors both in transient and steady-state operation. The terms of accuracy of the LS_SC_MRAS observers is quite high and it is robustness against motor parameter variations. From the comparison data have proven that the proposed NNVM_SC_MRAS observer is much better solution those known from the literature [17], [20], [21],[23] especially, at low and zero speed range.

The paper is organized into five sections. In Section 2, the basic theory of the model of the SPIM and the SPIM drive are presented. Section 3 introduces the proposed LS_ SC MRAS observer. Simulation and discuss are presented in Section 4. Finally, the concluding is provided in Section 5.

\section{MODEL VECTOR CONTROL OF SPIM DRIVES}

\subsection{Model vector control of SPIM drives}

The system under study consists of an SPIM fed by a six-phase VSI (voltage Source Inverter) and a DC link. A detailed scheme of the drive is provided in Figure 1. This SPIM is a continuous system that can be described by a set of differential equations. The model of the system can be simplified by means of the vector space decomposition (VSD). By applying this technique, the original six-dimensional space of the machine is transformed into three two-dimensional orthogonal subspaces in the stationary reference fame (D$\mathrm{Q}),(\mathrm{x}-\mathrm{y})$ and ( $\mathrm{zl}-\mathrm{z} 2)$. This transformation is obtained by means of 6 x 6 transformation matrix equation (1).

$$
\mathrm{T}_{6}=\frac{1}{3}\left[\begin{array}{cccccc}
1 & \frac{\sqrt{3}}{2} & -\frac{1}{2} & -\frac{\sqrt{3}}{2} & -\frac{1}{2} & 0 \\
0 & \frac{1}{2} & \frac{\sqrt{3}}{2} & \frac{1}{2} & -\frac{\sqrt{3}}{2} & -1 \\
1 & -\frac{\sqrt{3}}{2} & -\frac{1}{2} & \frac{\sqrt{3}}{2} & -\frac{1}{2} & 0 \\
0 & \frac{1}{2} & -\frac{\sqrt{3}}{2} & \frac{1}{2} & \frac{\sqrt{3}}{2} & -1 \\
1 & 0 & 1 & 0 & 1 & 0 \\
0 & 1 & 0 & 1 & 0 & 1
\end{array}\right]
$$

In that, an amplitude invariant criterion was used. From the motor model obtained by using the VSD approach, the following conclusions should be emphasized:

1. The electromechanical energy conversion variables are mapped to the (D-Q) subspace. The nonelectromechanical energy conversion variables can be found in other subspaces.

2. The current components in the (x-y) subspace do not contribute to the air gap flux so they should be controlled to be as small as possible.

3. The voltage vectors in the $(\mathrm{zl}-\mathrm{z} 2)$ are zero due to the separated neutrals configuration of the machine.

A VSI has a discrete nature, actually, it has a total number of $2^{6}=64$ different switching states defined by six switching functions corresponding to the six inverter legs [Sa,Sx,Sb,Sy,Sc,Sz], where Si $\epsilon$ $\{0,1\}$. On the other hand, a transformation matrix must be used to represent the stationary reference fame (D-Q) in the dynamic reference $(\mathrm{d}-\mathrm{q})$. This matrix is given:

$$
\mathrm{T}_{\mathrm{dq}}=\left[\begin{array}{cc}
\cos \left(\delta_{\mathrm{r}}\right) & -\sin \left(\delta_{\mathrm{r}}\right) \\
\sin \left(\delta_{\mathrm{r}}\right) & \cos \left(\delta_{\mathrm{r}}\right)
\end{array}\right]
$$




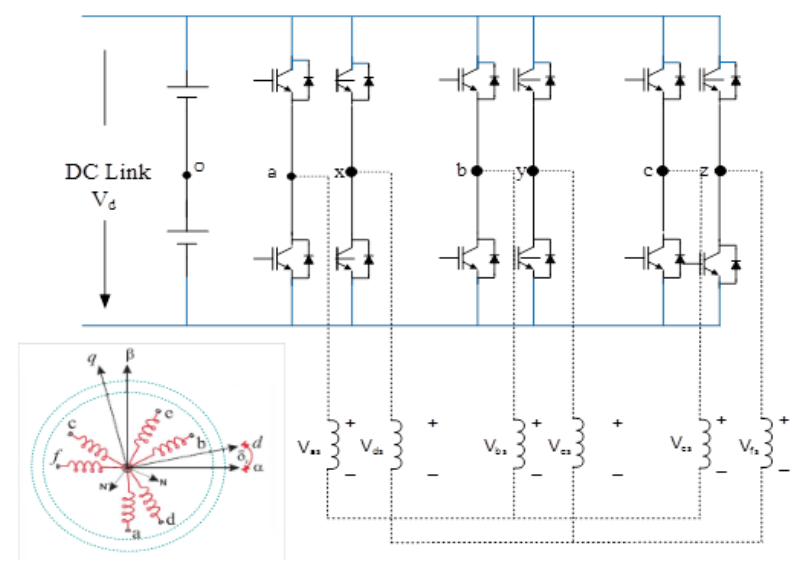

Figure 1. A general scheme of an SPIM drive
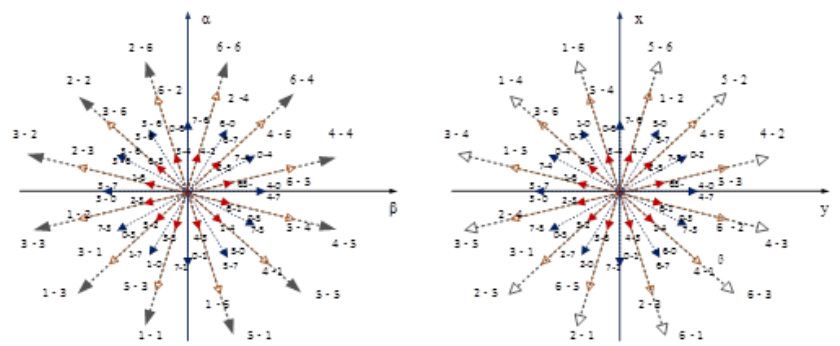

Figure 2. Switching states in (D-Q) and (x-y) subspaces for a SP VSI

The different switching states and the voltage of the DC link define the phase voltages which can in turn be mapped to the (D-Q) - (x-y) space according to the Vector space decomposition VSD approach.

\subsection{Model of SPIM}

In this part a six phase induction motor, which contains two sets of three phase winding spatially shifed by 30 electrical degrees with isolated neutral points (as depicted in Figure 1), is modeled. Stator and rotor voltage equation for this model is as follows:

$$
\begin{aligned}
& {\left[\mathrm{V}_{\mathrm{r}}\right]=\left[\mathrm{R}_{\mathrm{r}}\right]\left[\mathrm{I}_{\mathrm{r}}\right]+\mathrm{P}\left(\left[\mathrm{L}_{\mathrm{r}}\right]\left[\mathrm{I}_{\mathrm{r}}\right]+[\mathrm{M}]\left[\mathrm{I}_{\mathrm{s}}\right]\right)} \\
& {\left[\mathrm{V}_{\mathrm{s}}\right]=\left[\mathrm{R}_{\mathrm{s}}\right]\left[\mathrm{I}_{\mathrm{s}}\right]+\mathrm{P}\left(\left[\mathrm{L}_{\mathrm{s}}\right]\left[\mathrm{I}_{\mathrm{s}}\right]+[\mathrm{M}]\left[\mathrm{I}_{\mathrm{r}}\right]\right)}
\end{aligned}
$$

where: respectively, $[\mathrm{V}],[\mathrm{I}],[\mathrm{R}],[\mathrm{L}]$ and $[\mathrm{M}]$ are voltage, current, resistant, self and mutual inductance vectors. As these equations implies, the electromechanical conversion, only takes place in the D-Q subspace and the other subspaces just produce losses. So the torque equation can be written as follows:

$$
\begin{aligned}
& T_{e}=3 P\left(\Psi_{\beta r} i_{\alpha r}-\Psi_{\alpha r} i_{\beta r}\right) \\
& J_{i} \frac{d}{d t} \omega_{r}+B_{i} \omega_{r}=P\left(T_{e}-T_{L}\right)
\end{aligned}
$$

where: respectively, $\mathrm{Ji}, \omega \mathrm{r}, \mathrm{Bi}, \mathrm{Tm}, \mathrm{TL}, \mathrm{P}$ are inertia coefficient, angular speed, fiction factor, the electromagnetic torque that generated by the motor, load torque, number of poles and stator flux linkage at the related subspace.

\section{LS NN_SC_MRAS SPEED OBSERVER}

\subsection{PI SC MRAS observer}

In the classical rotor flux MRAS speed observer, the reference model, usually expressed as a Voltage Model (VM), represents the stator equation and can be written as following: 


$$
\begin{aligned}
& \frac{d \widehat{\Psi}_{r D}}{d t}=\frac{x_{r}}{x_{m}}\left(v_{s D}-r_{s} i_{s D}-\sigma T_{n} \mathrm{x}_{s} p i_{S D}\right) \\
& \frac{d \widehat{\Psi}_{r Q}}{d t}=\frac{x_{r}}{x_{m}}\left(v_{s Q}-r_{s} i_{s Q}-\sigma T_{n} \mathrm{x}_{s} p i_{s Q}\right)
\end{aligned}
$$

where: $\mathrm{r}_{\mathrm{s}}$ : stator resistances, $\mathrm{xs}=\mathrm{xm}+\mathrm{xs} \sigma ; \mathrm{xr}=\mathrm{xm}+\mathrm{xr} \sigma ; \mathrm{xm}$ : respectively stator, rotor reactances and magnetizing, xos, xor: stator and rotor leakage reactances, $\mathrm{p}=\mathrm{d} / \mathrm{dt}$; Tn $=1 / 2 \pi \mathrm{fsn}, \sigma=1-\mathrm{xm} 2 / \mathrm{xs} \mathrm{xr}$, fsn: nominal frequency. The adaptive model, usually represented by the Current Model (CM), describes the rotor equation where the rotor flux components are expressed in terms of stator current components and the rotor speed.

$$
\begin{aligned}
& \frac{\mathrm{d} \widehat{\Psi}_{r Q}}{d t}=\left[\frac{r_{r}}{x_{r}}\left(x_{m} i_{s D}-\Psi_{r D}\right)-\widehat{\omega} \Psi_{r Q}\right] T_{n} \\
& \frac{\mathrm{d} \widehat{\Psi}_{r Q}}{d t}=\left[\frac{r_{r}}{x_{r}}\left(x_{m} i_{s Q}-\Psi_{r Q}\right)+\widehat{\omega} \Psi_{r D}\right] T_{n}
\end{aligned}
$$

Looking at the formula (6), it is easy to find the presence of $r_{s}$ and rotor flux, These make the traditional RF_MRAS observer suffered by pure integration problems, which being able to cause dc drift and initial condition problems, and insensitive to motor parameter variations. In order to overcome these problems another approach, the stator current MRAS scheme has been proposed, the stator current components is used as a reference model. The stator current estimator is adjustable model. The estimated stator current components are compared with their measured values, and the signal $\mathrm{e}_{\text {is }}$ is used in the adaptation mechanism (9) to generate the rotor speed. In this observer, the mathematical model of the stator current observer can be calculated from the combined voltage and current models and is described by the following equation:

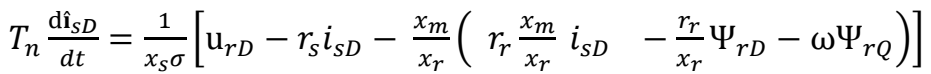

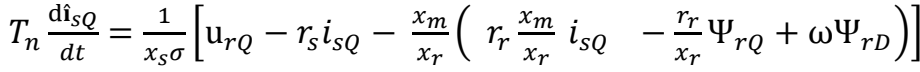

The adjustable model (8) requires information about the rotor flux. This is calculated on the basis of voltage model (VM) (6) or current model (CM) (7). In the PI_SC_MRAS observer, the used adaptation algorithm is based on the error between estimated and measured stator current developed in [24] (basing on the minimization of the Lyapunov function)

$$
\widehat{\omega}_{r}=\mathrm{K}_{\mathrm{p}}\left(\mathrm{e}_{i D} \Psi_{r Q}-\mathrm{e}_{i Q} \Psi_{r D}\right)+\mathrm{K}_{\mathrm{I}} \int\left(\mathrm{e}_{i D} \Psi_{r Q}-\mathrm{e}_{i Q} \Psi_{r D}\right) \mathrm{dt}
$$

where $e_{\mathrm{isD}}=\mathrm{i}_{\mathrm{sD}}-\mathrm{i}_{\mathrm{esD}}, \mathrm{e}_{\mathrm{isQ}}=\mathrm{i}_{\mathrm{sQ}}-\mathrm{i}_{\mathrm{esQ}}$ is the error between estimated and measured stator current. The obtained rotor speed value is used in the stator current estimator as changeable parameter, as shown in the Figure 3.

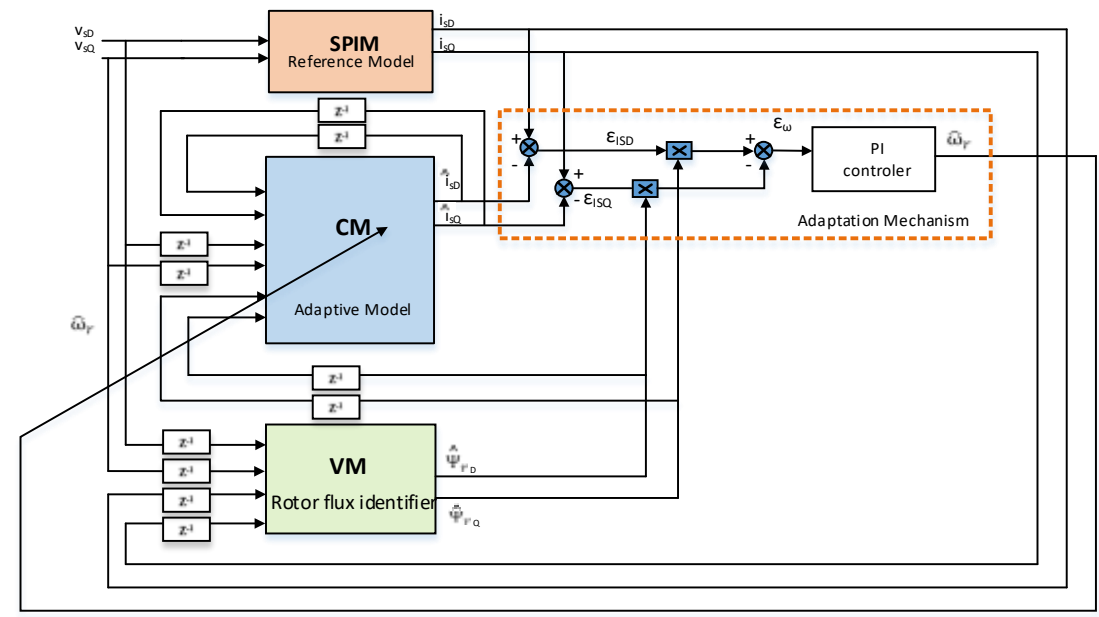

Figure 3. PI_SC_MRAS speed observer 


\subsection{S NN_SC MRAS observer}

\subsubsection{Structure of the LS_SC_MRAS Observer}

In this scheme, the measured stator current components are also used as the reference model of the MRAS observer to avoid the use of a pure integrator and reduce influence of motor parameter variation as in [22]-[23]. The adaptive model is a two-layer linear NN to estimate the stator current has been trained online by means of a least-squares algorithm. This adaptive model is described by the combined voltage- and current models in the stator reference frame (8). Equation (8), Then they been divided by Tn, be re written in the following as:

$$
\dot{X}=\mathrm{AX}+\mathrm{Bu}
$$

where

$$
\dot{X}=\left[\begin{array}{c}
\frac{d i_{s D}}{d t} \\
\frac{d i_{s Q}}{d t}
\end{array}\right] ; A=\left[\begin{array}{c}
-\left(1+\frac{x_{m}^{2}}{x_{r}^{2}}\right) \frac{r_{s}}{x_{s} \sigma} \\
-\left(1+\frac{x_{m}^{2}}{x_{r}^{2}}\right) \frac{r_{s}}{x_{s} \sigma}
\end{array}\right] ; B=\left[\begin{array}{ccccc}
\frac{1}{x_{s} \sigma} & 0 & \frac{1}{x_{s} \sigma} \frac{r_{r} x_{m}}{x_{r}^{2}} & \frac{1}{x_{s} \sigma} \frac{x_{m} \omega_{r}}{x_{r}} \\
0 & \frac{1}{x_{s} \sigma} & -\frac{1}{x_{s} \sigma} \frac{x_{m} \omega_{r}}{x_{r}} & \frac{1}{x_{s} \sigma} \frac{r_{r} x_{m}}{x_{r}^{2}}
\end{array}\right] ; \quad X=\left[\begin{array}{c}
i_{s D} \\
i_{s Q}
\end{array}\right] ; u=\left[\begin{array}{c}
v_{s D} \\
v_{s Q} \\
\widehat{\Psi}_{r D} \\
\widehat{\Psi}_{r Q}
\end{array}\right]
$$

Its corresponding discrete model is, therefore, given by:

$$
\widehat{X}(k)=e^{[A] T_{s}} X(k-1)+\left(e^{A T_{s}}-I\right) A^{-1} B u(k-1)
$$

$\mathrm{e}^{\mathbf{A} \mathbf{T}}$ : is generally computed by truncating its power series ex pansion, i.e.,

$$
e^{A T_{s}}=I+\frac{\mathrm{AT}_{s}}{1 !}+\frac{\mathrm{A}^{2} \mathrm{~T}_{s}}{2 !}+\cdots+\frac{\mathrm{A}^{\mathrm{n}} \mathrm{T}_{s}}{\mathrm{n} !}
$$

If $n=1$, the simple forward Euler method is obtained, which gives the following finite difference equation [15]-[17].

$$
\begin{aligned}
& \hat{\mathrm{l}}_{\mathrm{sD}}(\mathrm{k})=\mathrm{w}_{1} \hat{\mathrm{l}}_{\mathrm{sD}}(\mathrm{k}-1)+\mathrm{w}_{2} \mathrm{v}_{\mathrm{sD}}(\mathrm{k}-1)+\mathrm{w}_{3} \widehat{\mathrm{T}}_{\mathrm{rD}}(\mathrm{k}-1)+\mathrm{w}_{4} \widehat{\mathrm{\Psi}}_{\mathrm{rQ}}(\mathrm{k}-1) \\
& \hat{\mathrm{i}}_{\mathrm{sQ}}(\mathrm{k})=\mathrm{w}_{1} \hat{\mathrm{s}}_{\mathrm{sQ}}(\mathrm{k}-1)+\mathrm{w}_{2} \mathrm{v}_{\mathrm{sQ}}(\mathrm{k}-1)+\mathrm{w}_{3} \widehat{\mathrm{T}}_{\mathrm{rQ}}(\mathrm{k}-1)-\mathrm{w}_{4} \widehat{\mathrm{\Psi}}_{\mathrm{rD}}(\mathrm{k}-1)
\end{aligned}
$$

where marks the variables estimated with the adaptive model and is the current time sample. A neural network can reproduce these equations, where are the weights of the neural networks defined as:

$$
\mathrm{w}_{1}=1-\frac{\mathrm{T}_{\mathrm{s}} \mathrm{r}_{\mathrm{s}}}{\sigma \mathrm{L}_{\mathrm{s}}}-\frac{\mathrm{T}_{\mathrm{s}} \mathrm{L}_{\mathrm{m}}^{2}}{\sigma \mathrm{L}_{\mathrm{s}} \mathrm{L}_{\mathrm{r}} \mathrm{T}_{\mathrm{r}}} ; \mathrm{w}_{2}=\frac{\mathrm{T}_{\mathrm{s}}}{\sigma \mathrm{L}_{\mathrm{s}}} ; \mathrm{w}_{3}=\frac{\mathrm{T}_{\mathrm{s}} \mathrm{L}_{\mathrm{m}}}{\sigma \mathrm{L}_{\mathrm{s}} \mathrm{T}_{\mathrm{r}}} ; \mathrm{w}_{4}=\frac{\mathrm{T}_{\mathrm{s}} \mathrm{L}_{\mathrm{m}} \hat{\omega}_{\mathrm{r}}}{\sigma \mathrm{L}_{\mathrm{s}} \mathrm{L}_{\mathrm{r}}}
$$

where: $\hat{\mathrm{s}}_{\mathrm{s}}(\mathrm{k})$ the current variables estimated with the adaptive model and $\mathrm{k}$ is the current time sample, Ts is the sampling time for the stator current observer. The ANN has, thus, four inputs and two outputs [22]-[23]. In the ANN, the weights w1, w2 and w3 are kept constant to their values computed offline while only w4 is adopted online. These equations are the same as those obtained in [23]. In the scheme is presented in [23], the adaptive model is characterized by the feedback of delayed estimated stator current components to the input of the neural network, which means that the adaptive model employed is in simulation mode. Moreover, the adaptive model is tuned online (training) by means of a BPN algorithm, however, nonlinear in its nature with the consequent drawbacks (local minima, heuristics in the choice of the network parameters, paralysis, convergence problems).

In this LS_SC_MRAS observer proposed, the adaptive model based on the ADALINE has been improved, A linear least-square algorithm, which is more suitable than a nonlinear one, like the BPN, is used to reduce the computation effort and overcome some drawbacks, which cause by its inherent nonlinearity. Furthermore, the employment of the adaptive model in prediction mode leads to a quicker convergence of the algorithm, a higher bandwidth of the speed control loop, a better behavior at zero-speed, lower speed estimation errors both in transient and steady state conditions.

An integration method more efficient than that used in (15) is the so called modified Euler integration, which also takes into consideration the values of the variables in two previous time steps [25]. From (9), the following discrete time equations can be obtained, as shown in (15). Also, in this case, a neural network can reproduce these equations, where and are the weights of the neural networks defined as (16). 


$$
\begin{gathered}
\hat{\mathrm{i}}_{\mathrm{sD}(\mathrm{k})}=\mathrm{w}_{1} \mathrm{i}_{\mathrm{sD}(\mathrm{k}-1)}+\mathrm{w}_{2} \mathrm{u}_{\mathrm{sD}(\mathrm{k}-1)}+\mathrm{w}_{3} \hat{\psi}_{\mathrm{rD}(\mathrm{k}-1)}+\mathrm{w}_{4} \hat{\psi}_{\mathrm{rQ}(\mathrm{k}-1)}+\mathrm{w}_{5} \mathrm{i}_{\mathrm{sD}(\mathrm{k}-2)}-\mathrm{w}_{6} \mathrm{u}_{\mathrm{sD}(\mathrm{k}-2)}-\mathrm{w}_{7} \hat{\psi}_{\mathrm{rD}(\mathrm{k}-2)}-\mathrm{w}_{8} \hat{\psi}_{\mathrm{rQ}(\mathrm{k}-2)} \\
\hat{\mathrm{i}}_{\mathrm{sQ}(\mathrm{k})}=\mathrm{w}_{1} \hat{\mathrm{i}}_{\mathrm{sQ}(\mathrm{k}-1)}+\mathrm{w}_{2} \mathrm{u}_{\mathrm{sQ}(\mathrm{k}-1)}+\mathrm{w}_{3} \hat{\psi}_{\mathrm{rQ}(\mathrm{k}-1)}-\mathrm{w}_{4} \hat{\psi}_{\mathrm{rD}(\mathrm{k}-1)}+\mathrm{w}_{5} \mathrm{i}_{\mathrm{sQ}(\mathrm{k}-2)}-\mathrm{w}_{6} \mathrm{u}_{\mathrm{sQ}(\mathrm{k}-2)}-\mathrm{w}_{7} \hat{\psi}_{\mathrm{rQ}(\mathrm{k}-2)}+\mathrm{w}_{8} \hat{\psi}_{\mathrm{rD}(\mathrm{k}-2)} \\
\mathrm{w}_{1}=1-\frac{3 \mathrm{TR}_{\mathrm{s}}}{2 \sigma \mathrm{L}_{\mathrm{s}}}-\frac{3 \mathrm{TL}_{\mathrm{m}}^{2}}{2 \sigma \mathrm{L}_{\mathrm{r}} \mathrm{L}_{\mathrm{r}}} ; \mathrm{w}_{2}=\frac{3 \mathrm{~T}}{2 \sigma \mathrm{L}_{\mathrm{s}}} ; \mathrm{w}_{3}=\frac{3 \mathrm{TL}_{\mathrm{m}}}{2 \sigma \mathrm{L}_{\mathrm{r}} \mathrm{L}_{\mathrm{s}} \mathrm{T}_{\mathrm{r}}} ; \mathrm{w}_{4}=\frac{3 \mathrm{TL}_{\mathrm{m}}}{2 \sigma \mathrm{L}_{\mathrm{r}} \mathrm{L}_{\mathrm{s}}} \omega_{\mathrm{r}} ; \mathrm{w}_{5}=\frac{3 \mathrm{TR}_{\mathrm{s}}}{2 \sigma \mathrm{L}_{\mathrm{s}}}+\frac{\mathrm{TL}_{\mathrm{m}}^{2}}{2 \sigma \mathrm{L}_{\mathrm{r}} \mathrm{L}_{\mathrm{s}} \mathrm{T}_{\mathrm{r}}} ; \\
\mathrm{w}_{6}=\frac{\mathrm{T}}{2 \sigma \mathrm{L}_{\mathrm{s}}} ; \mathrm{w}_{7}=\frac{\mathrm{TL}_{\mathrm{m}}}{2 \sigma \mathrm{L}_{\mathrm{r}} \mathrm{L}_{\mathrm{r}}} ; \mathrm{w}_{8}=\frac{\mathrm{TL}_{\mathrm{m}}}{2 \sigma \mathrm{L}_{\mathrm{r}} \mathrm{L}_{\mathrm{s}}} \omega_{\mathrm{r}}
\end{gathered}
$$

Rearranging (15), the matrix equation is obtained in prediction mode; see (17). This matrix equation can be solved by any least square technique.

$$
\begin{aligned}
{\left[\begin{array}{l}
\frac{3 T L_{\mathrm{m}}}{2 \sigma \mathrm{L}_{\mathrm{r}} \mathrm{L}_{\mathrm{s}}} \hat{\psi}_{\mathrm{rQ}(\mathrm{k}-1)}-\frac{\mathrm{TL}_{\mathrm{m}}}{2 \sigma \mathrm{L}_{\mathrm{r}} \mathrm{L}_{\mathrm{s}}} \hat{\psi}_{\mathrm{rQ}(\mathrm{k}-2)} \\
-\frac{3 \mathrm{TL}_{\mathrm{m}}}{2 \sigma \mathrm{L}_{\mathrm{r}} \mathrm{L}_{\mathrm{s}}} \hat{\psi}_{\mathrm{rD}(\mathrm{k}-1)}+\frac{\mathrm{TL}_{\mathrm{m}}}{2 \sigma \mathrm{L}_{\mathrm{r}} \mathrm{L}_{\mathrm{s}}} \hat{\psi}_{\mathrm{rD}(\mathrm{k}-2)}
\end{array}\right] \omega_{\mathrm{r}(\mathrm{k}-1)}=} \\
{\left[\begin{array}{l}
\hat{\mathrm{i}}_{\mathrm{sQ}(\mathrm{k})}-\mathrm{w}_{1} \mathrm{i}_{\mathrm{sQ}(\mathrm{k}-1)}-\mathrm{w}_{2} \mathrm{u}_{\mathrm{sQ}(\mathrm{k}-1)}-\mathrm{w}_{3} \hat{\psi}_{\mathrm{rQ}(\mathrm{k}-1)}-\mathrm{w}_{5} \mathrm{i}_{\mathrm{sQ}(\mathrm{k}-2)}+\mathrm{w}_{6} \mathrm{u}_{\mathrm{sQ}(\mathrm{k}-2)}+\mathrm{w}_{7} \hat{\psi}_{\mathrm{rQ}(\mathrm{k}-2)} \\
\hat{\mathrm{i}}_{\mathrm{sQ}(\mathrm{k})}-\mathrm{w}_{1} \mathrm{i}_{\mathrm{sQ}(\mathrm{k}-1)}-\mathrm{w}_{2} \mathrm{u}_{\mathrm{sQ}(\mathrm{k}-1)}-\mathrm{w}_{3} \psi_{\mathrm{rQ}(\mathrm{k}-1)}-\mathrm{w}_{5} \mathrm{i}_{\mathrm{sQ}(\mathrm{k}-2)}+\mathrm{w}_{6} \mathrm{u}_{\mathrm{sQ}(\mathrm{k}-2)}+\mathrm{w}_{7} \psi_{\mathrm{rQ}(\mathrm{k}-2)}
\end{array}\right] }
\end{aligned}
$$

Matrix equation (17) can be written: $\mathrm{Ax} \approx \mathrm{b}$. This is a classical matrix equation of the type, where $\mathrm{A}$ is called a "data matrix", $\mathrm{b}$ is called an"observation vector," and $\omega_{\mathrm{r}}$ is the scalar unknown. In this application a classical LS algorithm in a recursive form has been employed; This algorithm is described in detail in [25],[26]. Figure 4 shows the block diagram of the LS_SC_ MRAS speed observer. In literature there exist three Least-Squares techniques, i.e. the Ordinary Least-Squares (OLS), the Total Least-Squares (TLS) and the Data Least-Squares (DLS) which arise when errors are respectively present only in b or both in A and in $\mathrm{b}$ or only in A. The LS technique solves for this problem by calculating the value of wr which minimises the sum of squares of the distances among the elements (ai, bi), with $\mathrm{i}=1, \ldots, \mathrm{m}$, and the line itself. OLS minimises the sum of squares of the distances in the $b$ direction (error only in the observation vector). TLS minimises the sum of squares in the direction orthogonal to the line (for this reason TLS is also called orthogonal regression) while DLS minimises the sum of squares in the A direction (errors only in the data matrix). In this paper, authors focus on analysing OLS algorithm.

$$
\begin{aligned}
& \mathrm{A}=\left[\begin{array}{l}
\mathrm{A}_{1} \\
\mathrm{~A}_{2}
\end{array}\right]=\left[\begin{array}{c}
\frac{3 T L_{\mathrm{m}}}{2 \sigma \mathrm{L}_{\mathrm{r}} \mathrm{L}_{\mathrm{s}}} \hat{\psi}_{\mathrm{rQ}(\mathrm{k}-1)}-\frac{T L_{\mathrm{m}}}{2 \sigma \mathrm{L}_{\mathrm{r}} \mathrm{L}_{\mathrm{s}}} \hat{\psi}_{\mathrm{rQ}(\mathrm{k}-2)} \\
-\frac{3 T L_{\mathrm{m}}}{2 \sigma \mathrm{L}_{\mathrm{r}} \mathrm{L}_{\mathrm{s}}} \hat{\psi}_{\mathrm{rD}(\mathrm{k}-1)}+\frac{T L_{\mathrm{m}}}{2 \sigma \mathrm{L}_{\mathrm{r}} \mathrm{L}_{\mathrm{s}}} \hat{\psi}_{\mathrm{rD}(\mathrm{k}-2)}
\end{array}\right] \\
& \mathrm{b}=\left[\begin{array}{l}
\mathrm{b}_{1} \\
\mathrm{~b}_{2}
\end{array}\right]=\left[\begin{array}{l}
\hat{\mathrm{i}}_{\mathrm{sQ}(\mathrm{k})}-\mathrm{w}_{1} \mathrm{i}_{\mathrm{sQ}(\mathrm{k}-1)}-\mathrm{w}_{2} \mathrm{u}_{\mathrm{sQ}(\mathrm{k}-1)}-\mathrm{w}_{3} \hat{\psi}_{\mathrm{rQ}(\mathrm{k}-1)}-\mathrm{w}_{5} \mathrm{i}_{\mathrm{sQ}(\mathrm{k}-2)}+\mathrm{w}_{6} \mathrm{u}_{\mathrm{sQ}(\mathrm{k}-2)}+\mathrm{w}_{7} \hat{\psi}_{\mathrm{rQ}(\mathrm{k}-2)} \\
\hat{\mathrm{i}}_{\mathrm{sQ}(\mathrm{k})}-\mathrm{w}_{1} \mathrm{i}_{\mathrm{sQ}(\mathrm{k}-1)}-\mathrm{w}_{2} \mathrm{u}_{\mathrm{sQ}(\mathrm{k}-1)}-\mathrm{w}_{3} \hat{\psi}_{\mathrm{rQ}(\mathrm{k}-1)}-\mathrm{w}_{5} \mathrm{i}_{\mathrm{sQ}(\mathrm{k}-2)}+\mathrm{w}_{6} \mathrm{u}_{\mathrm{sQ}(\mathrm{k}-2)}+\mathrm{w}_{7} \hat{\psi}_{\mathrm{rQ}(\mathrm{k}-2)}
\end{array}\right]
\end{aligned}
$$




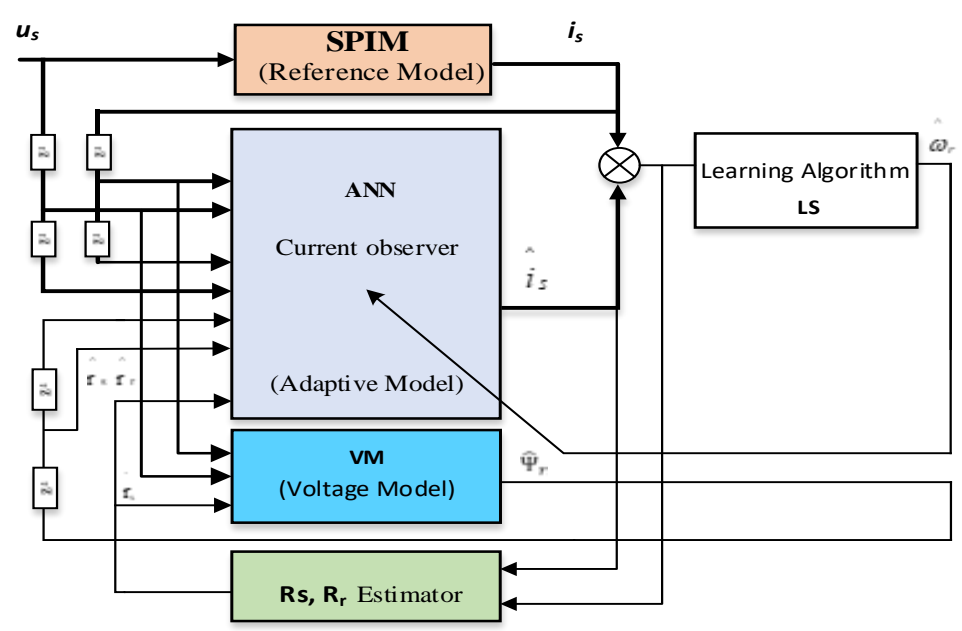

Figure 4. LS_SC_MRAS speed observer

\subsubsection{Rotor Speed Estimation Algorithm}

$\mathrm{Ax} \sim \mathrm{b}$ is the linear regression problem under hand. All LS problems have been generalized by using a parameterized formulation (generalized LS) of an error function whose minimization yields the corresponding solution. This error is given by:

$$
\mathbf{E}_{(X)}=\frac{(A x-b)^{\mathrm{T}}(A x-b)}{1-\xi+\xi X^{T} X}
$$

where T represents the transpose and $\xi$ is equal to 0.5 for TLS, 1 for DLS and 0 for OLS. Using OLS algorithm, this error is given by:

$$
\mathbf{E}_{\mathrm{OLS}}=(\mathrm{Ax}-\mathrm{b})^{\mathrm{T}}(\mathrm{Ax}-\mathrm{b})
$$

where:

$$
(\mathrm{Ax}-\mathrm{b})=\varepsilon=\left[\begin{array}{c}
\varepsilon_{\mathrm{isD}} \\
\varepsilon_{\mathrm{isQ}}
\end{array}\right]=\left[\begin{array}{l}
\mathrm{i}_{\mathrm{sD}}(\mathrm{k})-\hat{\mathrm{i}}_{\mathrm{sD}}(\mathrm{k}) \\
\mathrm{i}_{\mathrm{sQ}}(\mathrm{k})-\hat{\mathrm{i}}_{\mathrm{sQ}}(\mathrm{k})
\end{array}\right]
$$

This error can be minimized with a gradient descent method:

$$
\omega_{r}(k+1)=\omega_{r}(k)-\eta \gamma(k) a(k)
$$

where:

$$
\gamma(k)=a(k)^{T} x(k)-b(k)
$$

where $\eta$ is the learning rate, $\mathrm{a}(\mathrm{k})$ is the row of $\mathrm{A}$ fed at instant $\mathrm{k}$, and $\mathrm{b}(\mathrm{k})$ is the corresponding observation.

\subsubsection{Rotor Flux Estimation and Stator Resistance Online Estimation Algorithm}

From (15) can been seen that, the adaptive model generates stator current estimation values based on rotor speed information, stator voltages and rotor flux. In this proposed observer, the rotor flux values were generated base on equation (6) (VM).

$$
\begin{aligned}
& \frac{d \widehat{\Psi}_{r D}}{d t}=\frac{x_{r}}{x_{m}}\left(v_{s D}-r_{s} i_{s D}-\sigma T_{n} \mathrm{x}_{s} p i_{s D}\right) \\
& \frac{d \widehat{\Psi}_{r Q}}{d t}=\frac{x_{r}}{x_{m}}\left(v_{s Q}-r_{s} i_{s Q}-\sigma T_{n} \mathrm{x}_{s} p i_{s Q}\right)
\end{aligned}
$$

These rotor flux components are identified from the control voltage and the measured stator current. Using this VM to identify rotor flux will overcome the instability problem in the regenerating mode of 
operation, what appear using CM rotor flux identifier. From (6), (15) and (16), is easy see that, the resistance parameters necessary for estimating the speed. However, during motor operation, these parameters will change with the increase of temperature, especially, at low speed. Therefore to the performance improvement of the observer, especially at low speed, the resistances online identification is necessary.

In the proposed LS based adaptive speed observer the online $r_{s}$ estimation methodologies proposed in [27] have been used, summarized in the following. In particular Rs is estimated on the basis of the $\dot{i}_{s D}, i_{s D}$ measured and $\hat{\mathrm{i}}_{\mathrm{SD}}, \hat{\mathrm{i}}_{\mathrm{SQ}}$ estimated stator current components, by means of the following update law:

$$
\frac{d \hat{\mathbf{R}}_{\mathrm{s}}}{\mathrm{dt}}=-\mu\left(\left(\mathbf{i}_{\mathrm{sD}}-\hat{\mathbf{i}}_{\mathrm{sD}}\right) \hat{\mathbf{i}}_{\mathrm{sD}}+\left(\mathbf{i}_{\mathrm{sQ}}-\hat{\mathbf{i}}_{\mathrm{sQ}}\right) \hat{\mathbf{i}}_{\mathrm{sQ}}\right)
$$

where $\mu$ is a properly chosen positive constant. where $\lambda$ is a properly chosen positive constant. In this case, because it can not applied the same estimation scheme to rotor resistance estimation in sensorless drives, $\mathrm{Rr}$ has been estimated based on its variation proportional to that one of the Rs on the basis of the following law:

$$
\hat{\mathbf{R}}_{\mathrm{r}}=\mathbf{K}_{\mathrm{r}} \hat{\mathbf{R}}_{\mathrm{s}}
$$

where $\mathrm{Kr}$ is the ratio of the rated values of the stator and rotor resistances.

The estimated resistance values were update for the current observer to estimate the current exactly more.

\section{SIMULINK AND DISCUSSION}

In order to verify and evaluate the performance of the SC_MRAS using NN observer a sensorless vector control of SPIM drive system, as shown in Figure 5 has been simulated at different speed ranges through Matlab simulation software, specially surveyed at low speed range. Tests in this section are conducted based on recommended benchmark tests [17],[20],[21],[23]. SPIM parameters: 1HP, 220V, $50 \mathrm{~Hz}$, 4 pole, $1450 \mathrm{rpm}$. $\mathrm{Rs}=10.1 \Omega, \mathrm{Rr}=9.8546 \Omega, \mathrm{Ls}=0.833457 \mathrm{H}, \mathrm{Lr}=0.830811 \mathrm{H}, \mathrm{m}=0.783106 \mathrm{H}, \mathrm{Ji}=$ $0.0088 \mathrm{~kg} . \mathrm{m} 2$. Rs is nominal value of stator resistance.

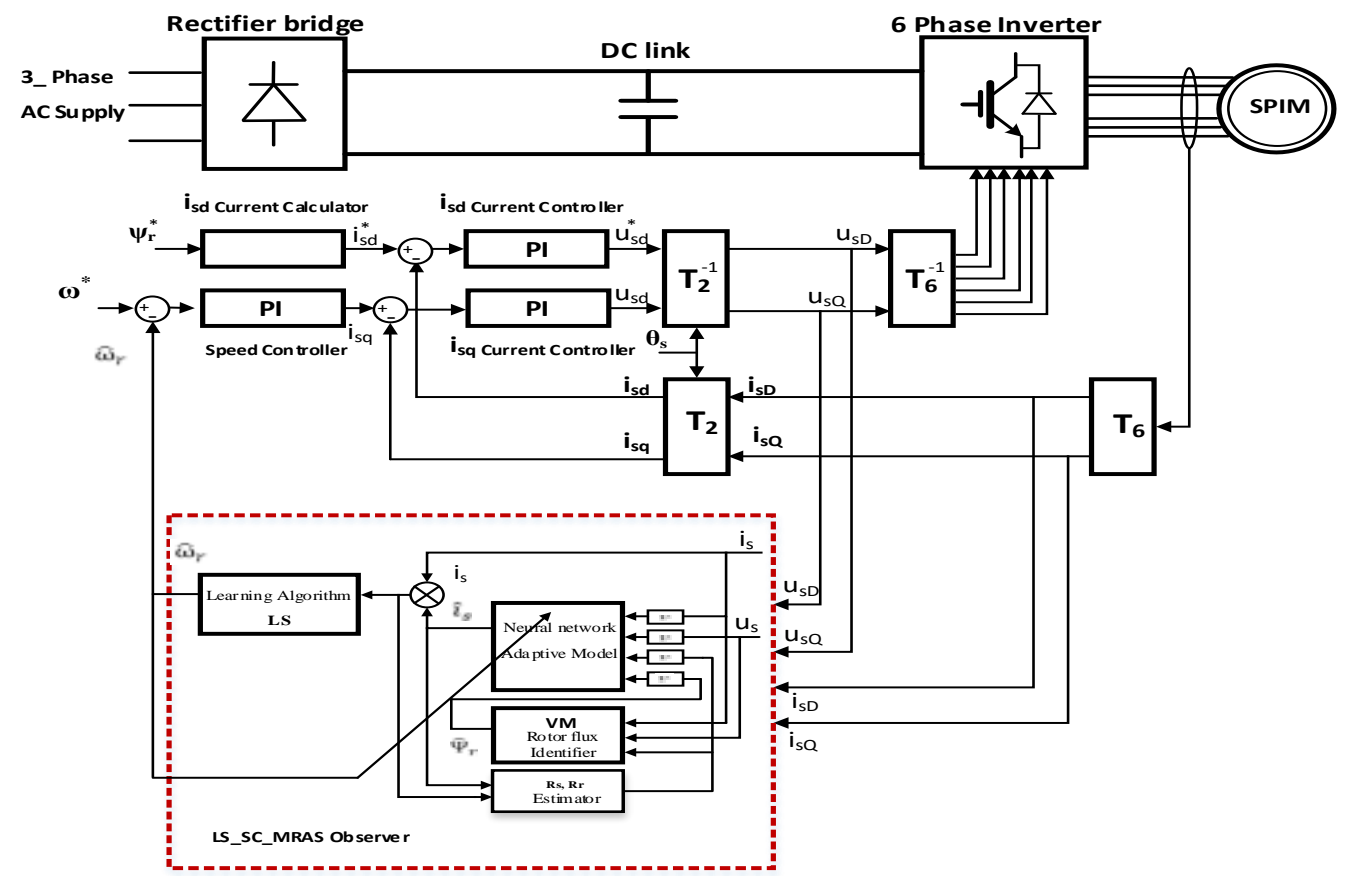

Figure 5. Sensorless vector control of SPIM drive using LS_SC_MRAS observer 


\subsection{Dynamic Performance}

In this first part, the dynamic performance of the drive and observer have been verified by the tests are conducted based on recommended Benchmark tests in [17]. Test 1 presents rapid transitions and operating areas at large and zero speeds, Test 2 consists of low and very low speed operation and reversal.

In Test 1, the reference speed are imposed from zero increased to $155 \mathrm{rad} / \mathrm{s}$ at $0.2 \mathrm{~s}$ and constant up to $1,5 \mathrm{~s}$. Then, it is reduced to zero at $1,7 \mathrm{~s}$, the reference speed is then maintained at standstill until $2,5 \mathrm{~s}$. Then, between $2,5 \mathrm{~s}$ and 4,8 s, a quasi-symmetric velocity profile is imposed in the opposite rotational direction, defining a second area of critical operating at a rate of $-155 \mathrm{rad} / \mathrm{s}$ between $4 \mathrm{~s}$ and $4,8 \mathrm{~s}$. Finally, the machine speed is again increased to $155 \mathrm{rad} / \mathrm{s}$, to be there maintained up to $6 \mathrm{~s}$. Rated load is applied at $0.8 \mathrm{~s}$ and rejected at 1.2s. The application and removal of a torque load at the moments $0,8 \mathrm{~s}$ and $1,2 \mathrm{~s}$ will also assess the impact of this type of disturbance. Then, 50\% load is applied and rejected at 3,25s and 5,5s, respectively. The results in Figure 6 show the speed responses, the speed estimation error, the stator current and torque during test 1 . From these simulation results show that although surveyed with larger speed range compare to in [17], the estimation performance of LS_SC_MRAS observer is very good at high, low and zero speed and reversal. The speed estimation error is the estimated speed perfectly follows the machine speed with good behavior in terms of tracking and disturbance rejection. Both the proposed scheme in [17] and LS_SC_MRAS scheme, the speed reversal is accomplished in less than 1s and that the torque response is instantaneous. The speed error is maximum at zero crossing and during the speed transient and it is about as much as $0.12 \mathrm{rad} / \mathrm{s}$ in LS_SC_MRAS observer, $0.5 \mathrm{rad} / \mathrm{s}$ in the proposed observer [17].
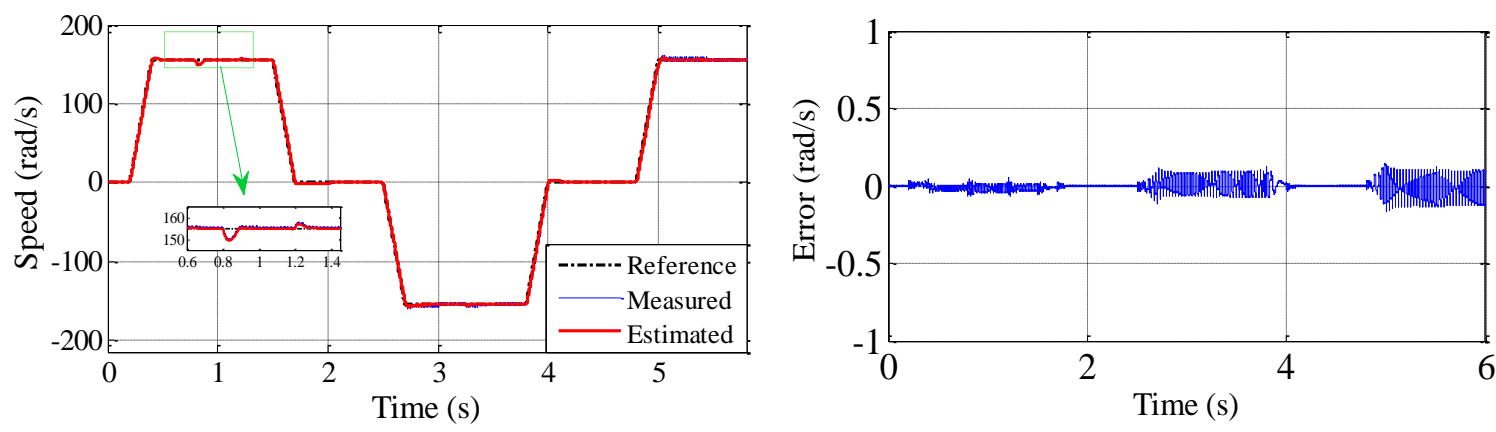

(a)
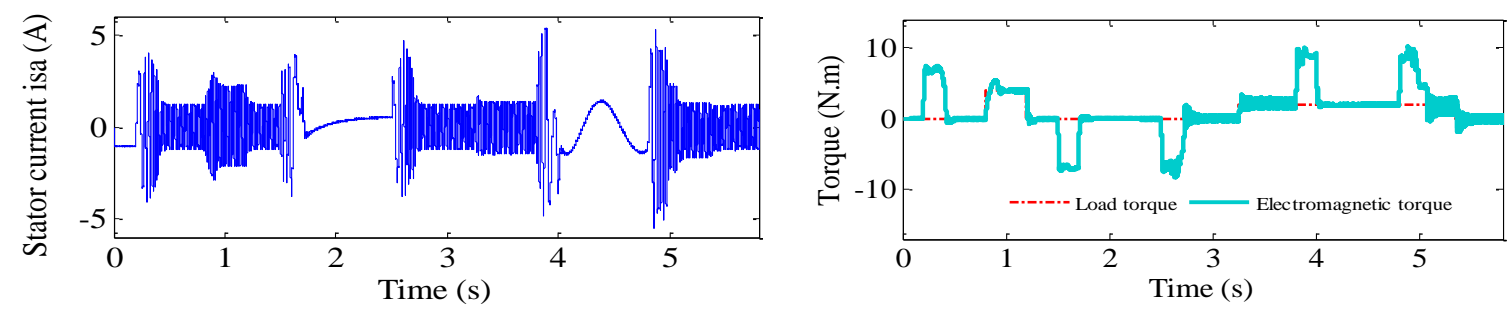

(b)

Figure 6. The performance of LS SC_MRAS obsever during high speed reveral (a) Speed responses and error, respectively; (b) Stator current phase A and torque respone

Furthermore, a speed reversal from $15 \mathrm{rad} / \mathrm{s}$ to $-8 \mathrm{rad} / \mathrm{s}$ and $8 \mathrm{rad} / \mathrm{s}$, at $50 \%$ load has been performed for testing the dynamic performances of the drive using LS-SC_MRAS at low speed. Figure 7 shows the speed and torque response of LS_SC_MRAS drive is very quick and that after few oscillations it converges to the reference value. We observe very small oscillations during transients and very low orientation errors in the two critical areas of the proposed observer. 

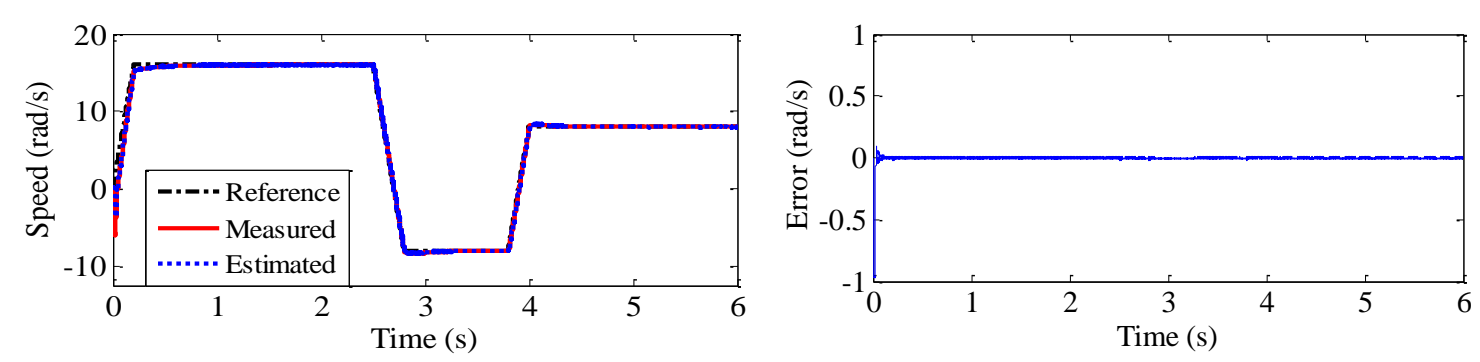

(a)
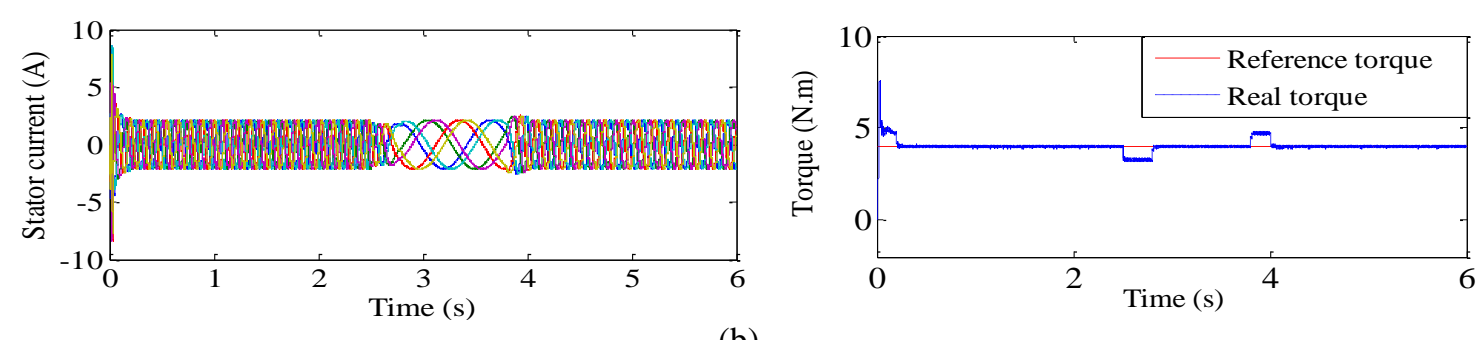

(b)

Figure 7. The performance of LS SC_MRAS obsever during low speed reveral (a) Speed responses and error, respectively; (b) Stator current six phase and torque response

From two above tests, It can be seen that, during speed transients the dynamic performance of LS_SC_MRAS is better, the maximum overshoot and the speed estimation error obtained with the LS MRAS observer are lower than the corresponding one with the observer [17]. The torque response obtained with the LS MRAS observer is very smooth, while the corresponding one obtained with the the proposed observer in [17] is much affected by ripple (Figure 6(b), 7(b)). The performance of the proposed scheme is very stable and very good in wide speed range.

The improvements in terms of dynamic performance achieved with the LS MRAS observer also have been verified by comparing the proposed of MRAS observers during speed reversals from 50 to - 50 $\mathrm{rad} / \mathrm{s}, 50 \%$ load in the transient mode to the proposed observer in [23]. Since the adaptive model of the BPN MRAS observer [23] is employed in simulation mode, the speed estimation convergence is slower than that obtained with the LS MRAS observer in prediction mode. In addition, the estimated speed is highly affected by the ripple and cannot be directly fed to the control system without any filtering. This is not the case for the LS MRAS observer in which, thanks to the employment of the adaptive model as a predictor, the estimated speed is directly fed back to the control system without any filtering. The simulation results in Figure 8 demonstrate better transient and steady state performance compared to the observer in [23], the LS MRAS observer permits a faster speed response, the time during which the speed reversal is performed is lower in all tests and this time reduction is in percentage more significant during a reversal at low speed, e.g., 0.052s with the LS MRAS against $0.101 \mathrm{~s}$ with the BPN MRAS.
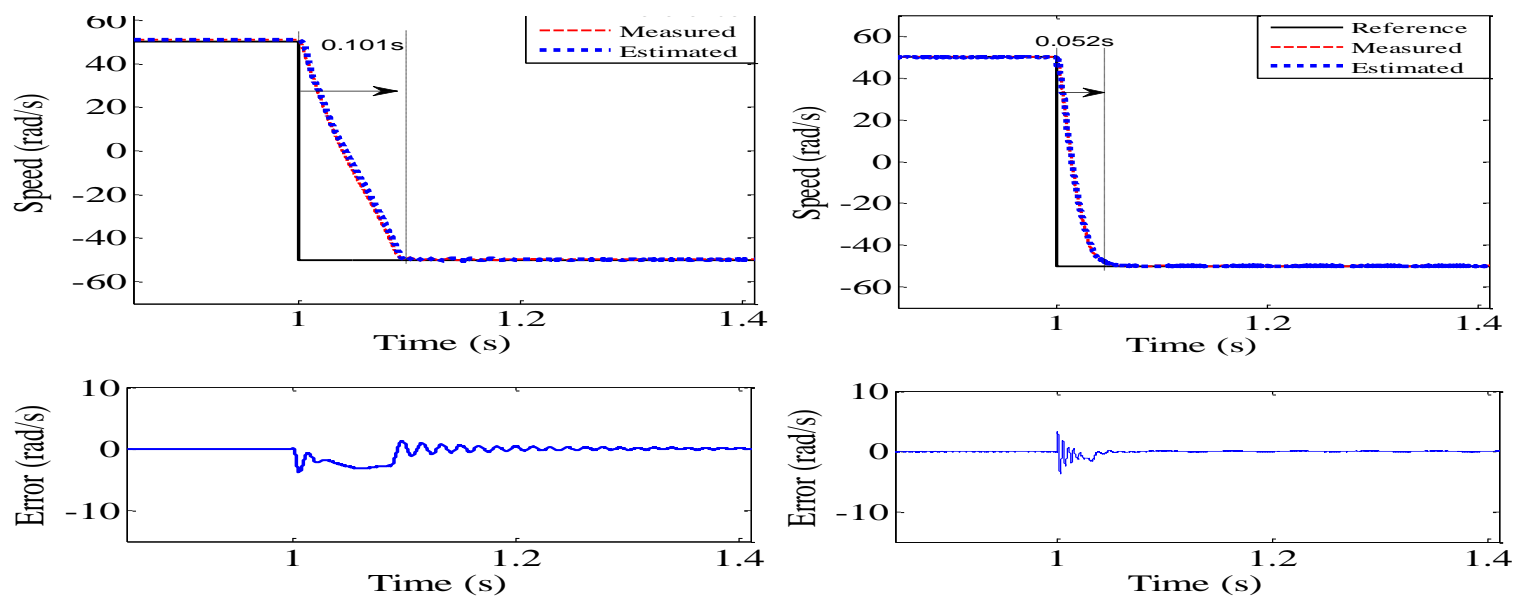

Int J Pow Elec \& Dri Syst, Vol. 9, No. 4, December 2018 : 1486 - 1502 


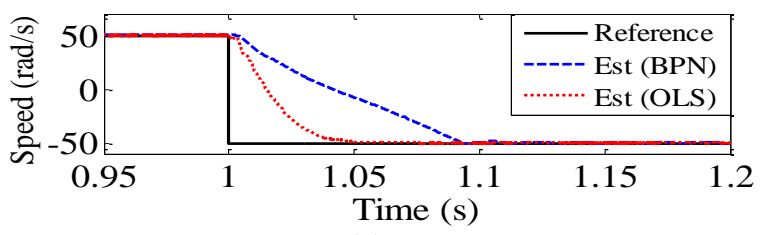

(a)

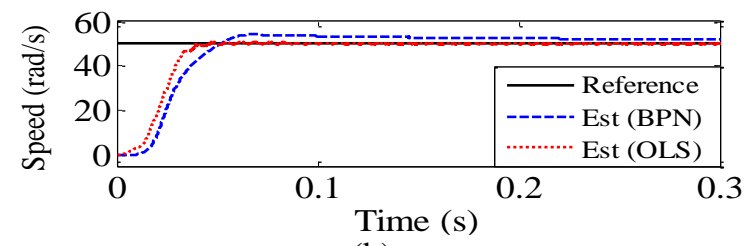

(b)

Figure 8. Estimated and measured speed and speed error and speed error during a speed reversal (a) BPN MRAS observer; (b) LS MRAS observer

\subsection{The performance of proposed observer in medium and low speed ranges:}

The performance of the proposed speed observer in the medium and low speed ranges was verified by providing different speed reference rates range from $100 \mathrm{rad} / \mathrm{s}$ to $30 \mathrm{rad} / \mathrm{s}$ and working with rated load.

This simulation was performed with two sets of observations using LS_SC_MRAS and BPN_SC_MRAS for comparison, evaluation the performance of both. The Figure 9 (a) and (b) shows the reference speed, estimated speed, actual speed and speed error of BPN_SC_MRAS observer [23] and LS_SC_MRAS, respectively. The simulation results clearly show that the estimation accuracy in the medium and low speed range is very good, with negligible estimation errors during steady state and very low instantaneous estimation errors during the speed transients. Similar results have been obtained with the BPN MRAS observer: they presented, as a difference, only a slightly higher instantaneous estimation error, as explained in Test 1 .
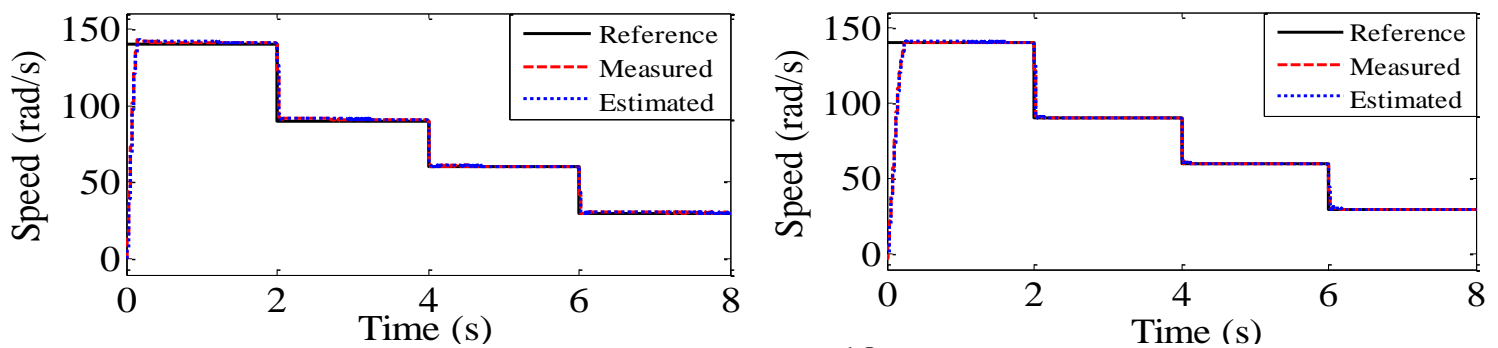

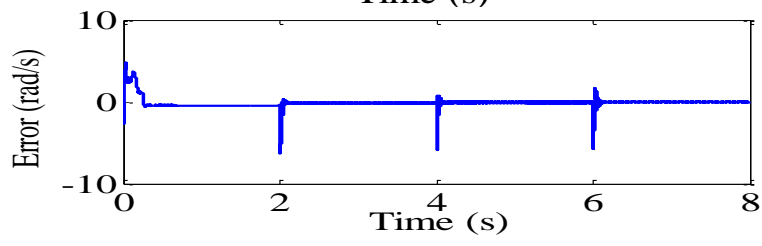

(a)

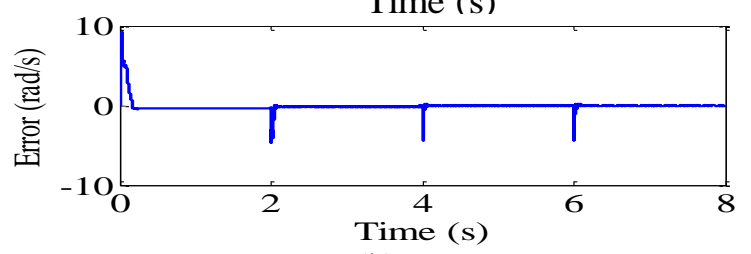

(b)

Figure 9. Speed responses and estimation error during a series of speed steps with rated load,

(a) BPN MRAS observer; (b) LS MRAS observer

\subsection{The performance of proposed observer in very low speed ranges:}

In this three test, the performance of the speed estimation has been verified in the very low and zero speed ranges based on proposed benchmark tests [21] but applying 50\%load. The drive has been given a speed reference step from $15 \mathrm{rad} / \mathrm{s}$ to zero then increase to $15 \mathrm{rad} / \mathrm{s}, 3 \mathrm{rad} / \mathrm{s}$ steps, $50 \%$ load applied at $2.5 \mathrm{~s}$ and rejected at 15s. Figure 10 (a) and (b) show the speed responses of proposed SC_MRAS at no load and $50 \%$ load, respectively. The results in Figure 10 show that no instability phenomena occur at low and zero speed range, the speed estimated error is not significantly. In contrast, with a proposed observer in [21] (Figure 6, Figure 7) shows instability phenomena, the estimated error increase at low and zero speed range. 


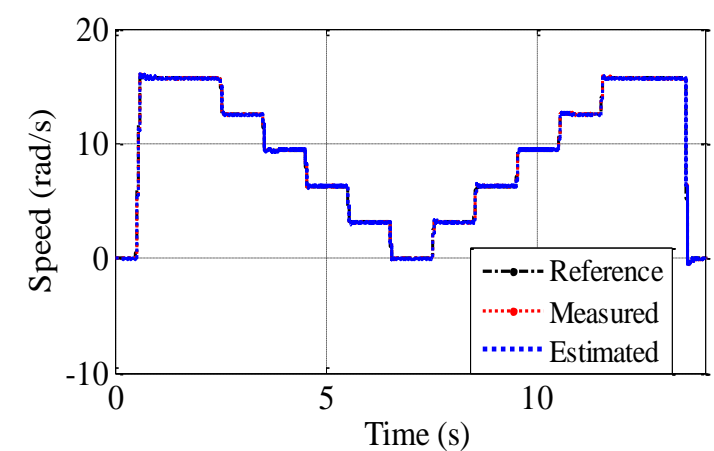

(a)

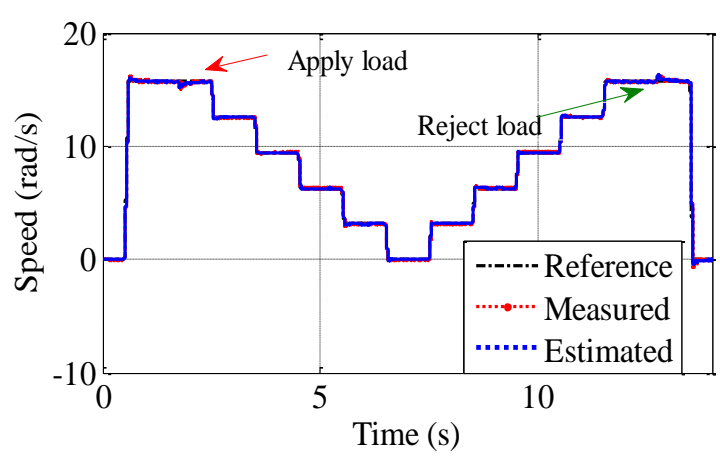

(b)

Figure 10. The speed of the SPIM in very low operation speed region using: (a) no load; (b) 50\% load

Another survey also is carried out to justify the effectiveness of the proposed method in the low and zero speed region by providing the sets of diffrrent speed reference ranges from 0 to $5 \mathrm{rad} / \mathrm{s}$ with each step the change is $1 \mathrm{rad} / \mathrm{s}$ working with $50 \%$ rated load. In any case, better results in the estimation accuracy at low speeds are to be expected with both LS MRAS and BPN MRAS observers [23] because the SPIM itself is used as reference model so the SC_MRAS observer free free from stator resistance dependency and dc drift problems, this is help to improve the performance of the observer specially at low speeds. The steadystate percent speed estimation error obtained with the LS_SC_MRAS observer is better than that with the RF_ MRAS observer, where the reference model uses the VM, is dependent on the stator stator and the pure integration. The speed estimation error is improved slightly than BPN_SC_MRAS, as explained in Test 1. These results in Figure 11 show that, with both speed observers, the steady-state speed estimation error obtained with the LS MRAS observer is slightly lower than that with the BPN_SC_MRAS.
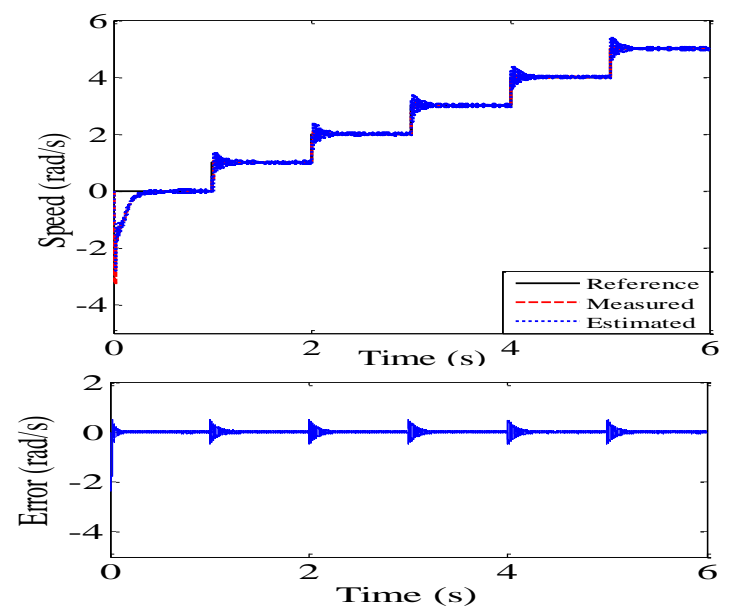

(a)
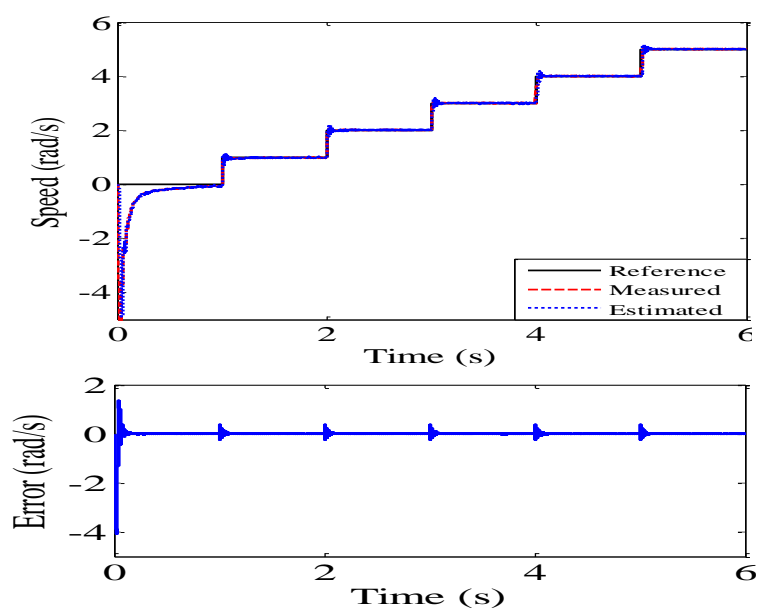

(b)

Figure 11. The speed of the SPIM in very low speed region using: (a) BPN SC_MRAS; (b) LS_SC_MRAS

\subsection{Sensitivity to Stator Resistance Variation:}

The purpose of this test is to verify the speed estimation performance of the proposed MRAS observers for motor parameter variation. The drive and observer have been verified based on recommended benchmark tests in [20] but extending survey additionally case the resistance values increase 50\%. Figure 12 shows the performance of the observer when Rs, $\mathrm{Rr}$ variations ( $\mathrm{Rs}, \mathrm{Rr}$ is increased $30 \%$ and $50 \%$ at $1.5 \mathrm{~s}$ and $3.5 \mathrm{~s}$, respectively, load is applied at $2 \mathrm{~s}$. The reference speed is reduced from $20 \mathrm{rad} / \mathrm{s}$ to $12 \mathrm{rad} / \mathrm{s}$ to $7 \mathrm{rad} / \mathrm{s}$ to zero. The stable operation and oscillating speed performance of the LS SC_MRAS observer and proposed observer in [21] (Figure 9) obtained are quite good. As we know that the stator resistance variation with temperature, which can be up to $50 \%$, is a very serious problem at low speed. Since the fundamental 
component of the stator voltage becomes very low, the stator resistance drop becomes comparable to the applied voltage. Hence continuous adaptation of the stator resistance is required to maintain stable operation at low speed [20]. However, the performance of the observer with the Rs variation increased more than $20 \%$ and the lower speed operation ranges were not shown in [21].

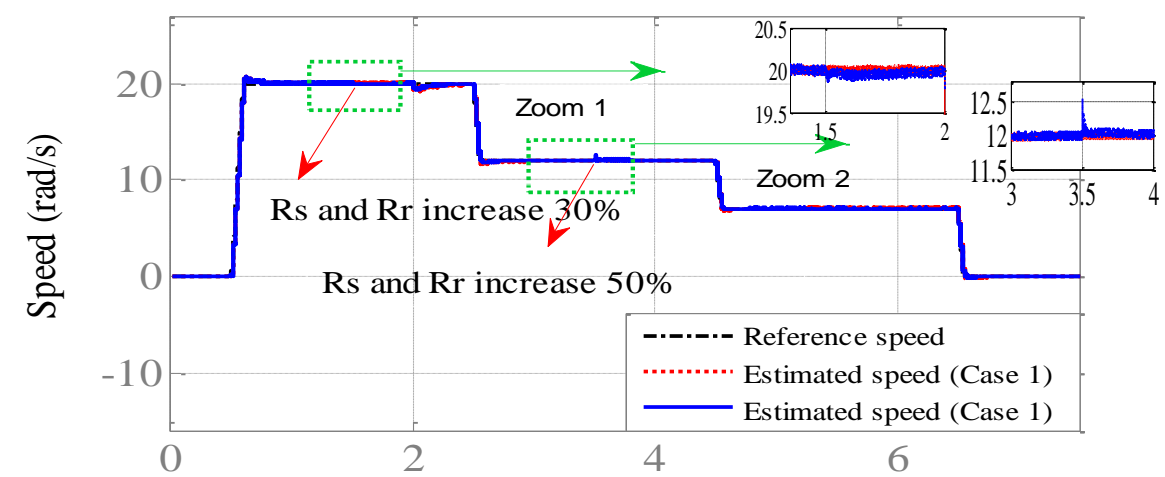

(a)

Time (s)

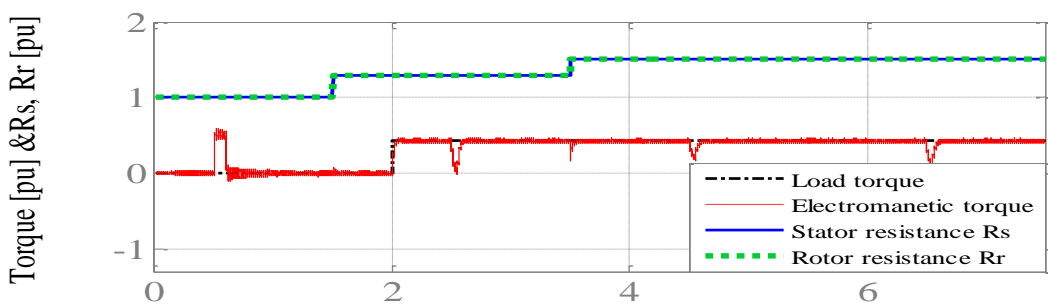

(b)

Time (s)

Figure 12. (a) The LS_SC_MRAS observer: Reference, actual, estimated speed for load torque and $R s, R r$ variations; (b) Load torque and $R s$ variations

\subsection{Load Perturbations}

In this test, the robustness of the speed estimation of the observer to a sudden torque perturbation has been surveyed. It was carried out to prove the behavior of the proposed scheme when load torque variations. For this test the rotor speed was kept constant at $7 \mathrm{rad} / \mathrm{s}$ with the torque applied $+/-50 \%$ rated torque. Figure 13(a) and (b) show the speed and torque responses of the SPIM drive. These results show that the speed responses of the drive using the proposed LS SC_MRAS observer occurs immediately when the torque steps are applied. Even during the speed transient that caused by the torque step, the estimated speed follows the real speed is very good. The simulation results show that the speed estimation convergence of the LS_SC_MRAS observer is faster than that obtained with the BPN SC_MRAS observer [23] thanks the improvements are developed.

The behavior of the proposed scheme with rotor speed was kept by zero during test, the speed estimation performance for load disturbance rejection at $+25 \%$ load in time $1.5 \mathrm{~s}-3 \mathrm{~s}$; $-25 \%$ load in time $3 \mathrm{~s}-$ 4.5s; and $6 \mathrm{~s}-7.5 \mathrm{~s} ; 75 \%$ load in 9s- 10.5. The proposed SC_MRAS scheme shows transient and steady state performance are very good. Figure 14 show the reference, measured, and estimated speed, these results show that the speed responses of the drive using the proposed NN SC_MRAS observer occurs immediately when the torque steps are given. The small oscillations occur when $75 \%$ load rejected, however, very low estimation errors of the proposed observer, even during the speed transient that caused by the torque step, the estimated speed follows the real speed is very good. 

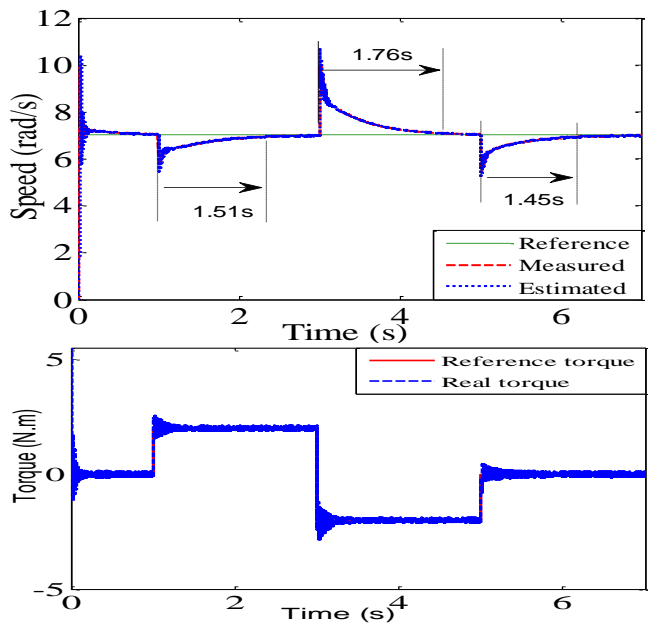

(a)
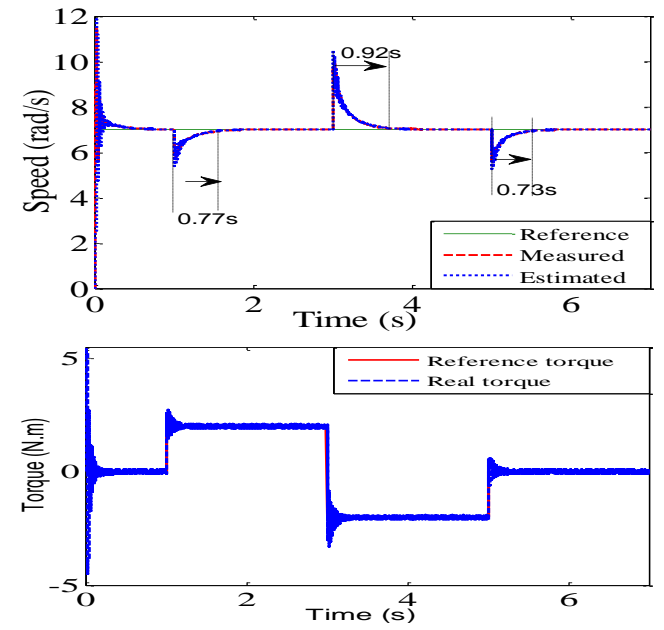

(b)

Figure 13. Load Perturbations test: (a.) the LS MRAS observer; (b) the BPN MRAS observer
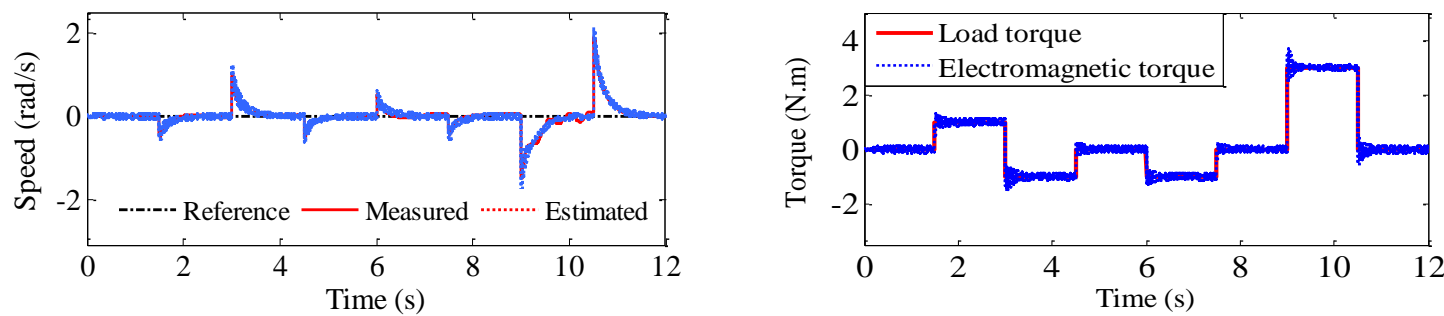

Figure 14. Load Perturbations test at zero speed, load torque various

\section{CONCLUSION}

This paper has presented a LS_SC_MRAS speed observer for high performance SPIM drives using neural networks. It lead evoluting and improving the MRAS observer shown in [23]. The new SC_MRAS speed observer uses the CM discretized with the mopdified Euler integration method to solve the instability problems due to the discretization of the rotor equations of the machine. Then reagraning a linear neural network is used and trained online by means of an LS algorithm instead of a nonlinear BPN algorithm, which is heavier from the complexity and computational burden and its inherent nonlinearity also cause some disadvantages as local minima, two heuristically chosen parameters, initialization, and convergence problems, paralysis of the neural network. In the proposed observer, stator and rotor resistance values are estimated online, these values thereafter were updated for the current observer and rotor flux identifier to enhance the accuracy, robustness and insensitivity to parameters variation for the proposed observer. In addition, the adaptive model based on $\mathrm{NN}$ is implement in prediction mode instead of simulation mode as in [23]. This ensures the proposed observer operate better accuracy and stability. The simulation results shown that the proposed observer are quicker convergence in speed estimation, better dynamic performances; lower estimation errors both in transient and steady state operation; better operation zeroand low speed region.

\section{REFERENCES}

[1] Levi E., "Multiphase electric machines for variable-speed applications," IEEE Transactions on Industrial Electronics, vol/issue: 55(5), pp. 1893-1909, 2008.

[2] Kubota H., et al., "DSP-based speed adaptive flux observer of induction motor," IEEE Trans. Ind. Appl., vol/issue: 29(2), pp. 344-348, 1993.

[3] Vieira R., et al., "Discrete-time sliding mode speed observer for sensorless control of induction motor drives," IET Electr. Power Appl., vol/issue: 6(9), pp. 681-688, 2012.

[4] Jafarzadeh S., et al., "State estimation of induction motor drives using the unscented Kalman filter," IEEE Trans. Ind. Electron, vol/issue: 59(11), pp. 4207-4216, 2012. 
[5] Schauder, "Adaptive speed identification for vector control of induction motors without rotational transducers," IEEE Trans. Ind. Appl., vol/issue: 28(5), pp. 1054-1061, 1992.

[6] RaviTeja A. V., et al., "A new model reference adaptive controller for four quadrant vector controlled induction motor drives," IEEE Trans. Ind. Electron., vol/issue: 59(10) pp. 3757-3767, 2012.

[7] M. S. Verma V. and Chakraborty C. H., "An adaptive speed sensorless induction motor drive with artificial neural network for stability enhancement," IEEE Trans. Ind. Inf., vol/issue: 8(4), pp. 757-766, 2012.

[8] Yaman B., et al., "Model Predictive MRAS Estimator for Sensorless Induction Motor Drives," IEEE Trans. Ind. Electronics, vol/issue: 63(6), pp. 3511-3521, 2016.

[9] Abdelhak B. and Bachir B., "A High Gain Observer Based Sensorless Nonlinear Control of Induction Machine," International Journal of Power Electronics and Drive System (IJPEDS), vol/issue: 5(3), pp. 305-314, 2015.

[10] Flah A. and Sbita L., "An adaptive high speed PMSM control for electric vehicle application," Journal of Electrical Engineering, vol/issue: 12(3), pp. 165-177, 2012.

[11] F. G. Rahman, "Sensorless sliding-mode MTPA control of an IPM synchronous motor drive using a sliding-mode observer and HF signal injection," IEEE Trans. Ind. Electron., vol/issue: 57(4), pp. 1270-1278, 2010.

[12] Flah A., et al., "An Improved Reactive Power MRAS Speed Estimator With Optimization for a Hybrid Electric Vehicles Application,” J. Dyn. Syst. Meas. Control, vol/issue: 140(6), pp. 061 016, 2018.

[13] Holtz, "Sensorless control of induction motor drives," Proc. of the IEEE, vol/issue: 90(8), pp. 1359-1394, 2002.

[14] Flah A., et al., "Online MRAS-PSO PMSM parameters estimation," International Review on Modelling and Simulations, vol/issue: 4(3), pp. 980-987, 2011.

[15] Holtz J. and Quan J., "Drift and parameter compensated flux estimator for persistent zero stator frequency operation of sensorless controlled induction motors," IEEE Trans. Ind. Appl., vol/issue: 39(4), pp. 1052-1060, 2003.

[16] C. Schauder, "Adaptive speed identification for vector control of induction motors without rotational transduce," IEEE Trans. Ind. Appl., vol/issue: 28(5), pp. 1054-1061, 1992.

[17] Horch M., et al., "MRAS-based Sensorless Speed Integral Backstepping Control for Induction Machine, using a Flux Backstepping Observer," International Journal of Power Electronics and Drive System (IJPEDS), vol/issue: 8(4), pp. 1650-1662, 2017.

[18] Jannati M., et al., "Indirect Rotor Field-Oriented Control of Fault-Tolerant Drive System for Three-Phase Induction Motor with Rotor Resistance Estimation Using EKF," TELKOMNIKA Indonesian Journal of Electrical Engineering, vol/issue: 12(9), pp. 6633-6643, 2014.

[19] Jannati M., et al., "Speed Sensorless Direct Rotor Field-Oriented Control of Single Phase Induction Motor Using Extended Kalman Filter," International Journal of Power Electronics and Drive System (IJPEDS), vol/issue: 4(4), pp. 430-438, 2014.

[20] Benlaloui I., et al., "Implementation of a New MRAS Speed Sensorless Vector Control of Induction Machine," IEEE Transactions on Energy Conversion, vol/issue: 30(2), pp. 588-595, 2015.

[21] Smith A. N., et al., "Improved Rotor Flux Estimation at Low Speeds for Torque MRAS-Based Sensorless Induction Motor Drives," IEEE Transactions On Energy Conversion, vol/issue: 31(1), pp. 270-282, 2016.

[22] S. M. Gadoue, et al., "An experimental assessment of a stator current MRAS based on neural networks for sensorless control of induction machines," Proc. 2011 Symp. Sensorless Control for Electrical Drives, Birmingham, $U K$, pp. 102-106, 2011.

[23] Shady M. G., et al., "Stator current model reference adaptive systems speed estimator for regenerating-mode lowspeed operation of sensorless induction motor drives," IET Electr. Power Appl., vol/issue: 7(7), pp. 597-606, 2013.

[24] Kowalska T. O. and Dybkowski M., "Stator-Current-Based MRAS Estimator for a Wide Range Speed-Sensorless Induction-Motor Drive," IEEE Transactions On Industrial Electronics, vol/issue: 57(4), pp. 1296-1308, 2010.

[25] Matheus J. H. and Fink K. D., "Numerical Methods Using Matlab," 4th ed. Upper Saddle River, NJ: PrenticeHall, 2004.

[26] Cirrincione G., et al., "The MCA EXIN neuron for the minor component analysis: Fundamentals and comparisons," IEEE Trans. Neural Netw., vol/issue: 13(1), pp. 160-187, 2002.

[27] Kubota H., et al., "DSP-Based Speed Adaptive Flux Observer of Induction Motor," IEEE Trans. Ind. Appl., vol/issue: 29(2), pp. 344-348, 1993.

\section{BIOGRAPHIES OF AUTHORS}

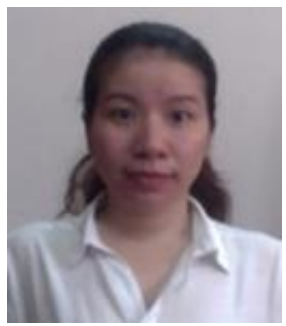

Ngoc Thuy Pham was born in Viet Nam, in 1976. She received the B.Sc degrees in Electrical Engineering from Thai Nguyen University of Technology in 1994, and the M.Sc from Ho Chi Minh City University of Technology in 2009. She has been in the Faculty of Electrical Engineering, Industrial University of Ho Chi Minh City from 2000. Her current research interests include the PWM techniques for power converters. AC motor drives, multiphase induction motor, sensorless control of multiphase induction motor drives. 


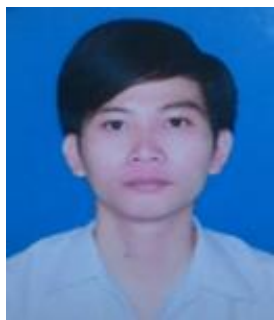

Diep Phu Nguyen was born in 1993. He received the B.Sc degrees in Electrical Engineering from Industrial University of Ho Chi Minh City in 2015. He is currently an engineer in the OneMember Limited-Liability Oil \& Gas Company of HoChiMinh City. His current research interests include the PWM techniques for power converters, AC motor drives, sensorless control of multiphase induction motor drives

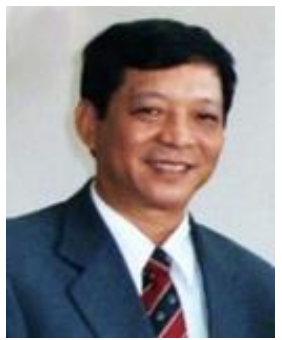

Khuong Huu Nguyen was born in Viet Nam, in 1956. he received the B.Sc degrees in Technical control from Vietnam Maritime University in 1978 and Ph.D. degrees from Moscow institute of electronics and mathematics in 1999. Since 1979, he has been with the Dept. Telecommunication Electronics and Electrical Engineering, Ho Chi Minh City University of Transport, Vietnam, where he is currently an Associate Professor. His research interests include Automatic control and automation of processes. The systems, equipment in the field of transport.

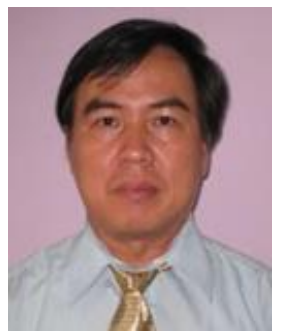

Nho Van Nguyen was born in Vietnam in 1964. He received his M.S. and Ph.D. degrees in Electrical Engineering from the University of West Bohemia, the Czech Republic in 1988 and 1991 respectively. Since 1992, he has been with the Department of Electrical and Electronics Engineering, Ho Chi Minh City University of Technology, Vietnam, where he is currently an Associate Professor. His research interests include AC motor drives, active power filters, and PWM techniques for power converters. He is a member of the Institute of Electrical and Electronics Engineers (IEEE) 